\title{
A multi-objective set covering problem: A case study of warehouse allocation in truck industry
}

\author{
Atefeh Malekinezhad $^{\mathrm{a}^{*}}$, Ehsan Shirazi ${ }^{\mathrm{a}}$ and M. B. Aryanezhad ${ }^{\mathrm{b}}$ \\ ${ }^{a}$ Department of Industrial Engineering, Islamic Azad University, Sought Branch, Tehran Iran \\ ${ }^{b}$ Department of Industrial Engineering, Iran University of Science and Technology, Narmak, Tehran Iran

\begin{tabular}{|c|c|}
\hline$\overline{\text { AR T I C L E I N F O }}$ & A B S T R A C T \\
\hline $\begin{array}{l}\text { Article history: } \\
\text { Received } 1 \text { June } 2010 \\
\text { Received in revised form } \\
10 \text { September } 2010 \\
\text { Accepted } 15 \text { September } 2010 \\
\text { Available online } \\
15 \text { September } 2010 \\
\text { Keywords: } \\
\text { Set covering } \\
\text { TOPSIS } \\
\text { Multi-objective } \\
\text { Distribution centers } \\
\text { Supply chain management }\end{array}$ & $\begin{array}{l}\text { Designing distribution centers is normally formulated as a set covering problem where the } \\
\text { primary objective is to minimize the number of connected facilities. However, there are other } \\
\text { issues affecting our decision on selecting suitable distribution centers such as weather } \\
\text { conditions, temperature, infrastructure facilities, etc. In this paper, we propose a multi-objective } \\
\text { set covering technique where different objectives are considered in an integrated model. The } \\
\text { objectives are in two parts of quantitative and qualitative. Two methods of analytical hierarchy } \\
\text { process (AHP) and TOPSIS are implemented to change the qualitative numbers into } \\
\text { quantitative numbers. A utility function is implemented to convert two objectives into a single } \\
\text { objective and the resulted model is solved using a regular mixed integer programming. The } \\
\text { proposed model of this paper is implemented for a real-world case study of truck-industry and } \\
\text { the results are analyzed in different scenarios. }\end{array}$ \\
\hline
\end{tabular}

\section{Introduction}

The Set covering has been one of the most interesting areas of research among many researchers since there are many real-world applications where this type of problem could be used (Vasko \& Wilson, 1984; Francis et al., 1992; Berman et al., 2003; Korsvik et al., 2011). The issue becomes more interesting when there is more than one single objective in the model. The primary objective of a traditional set covering is to connect different facilities with minimum distances (Church, \& ReVelle, 1974; Schilling et al., 1993; Hale \& Moberg, 2003). Such a problem is often formulated as a zero-one programming with some linear constraints. The number of binary variables in the model normally represents the number of alternative facilities which are supposed to be connected. A simple mixed integer programming method can be used to solve the resulted problem formulation whenever there are limited numbers of alternatives involved in the problem, say less than one hundred. However, as the number of alternative increases, the resulted problem becomes hard to solve. One possible alternative is to use the recent advances of heuristic or meta-heuristic approaches to solve this kind of problem (Solar et al., 2002; Aickelin, 2003). The distance is traditionally a simple

* Corresponding author. Tel: +98-09125177365

E-mail addresses: atefeh_malekinejad@yahoo.com (A. Malekinezhad), 
parameter involved with many set covering problems which could be considered with uncertainty (Chiang et al., 2005; Araz et al., 2005; Klose \& Drexl, 2005; Zyl \& Cloete, 2006). Recently, there have been growing interests in developing classical methods with different objectives which are mostly in conflict. These kinds of problems are often solved using the advances of multiple criteria decision making (Hwang \& Yoon, 1981). There are also cases where different objectives are involved with set covering problem (Boffey \& Narula, 1997; Nozick, \& Mark, 2001; Zanjirani Farahani \& Asgari, 2007). In fact, there are many cases where an implementation of a classical set covering leads us to have a solution with minimum connections but the selected alternatives cannot be chosen for many managerial reasons such as whether conditions, infrastructure problems, etc. In this paper, we present a multi-objective set covering problem where we have different qualitative and quantitative objectives involved with the proposed problem. The proposed model of this paper uses AHP and TOPSIS to rank the qualitative objectives. A utility function is then used to combine two objectives and the resulted problem is solved using a mixed integer programming. The resulted problem formulation is implemented for a real-world case study of truck-industry and the results are analyzed based on different scenarios. This paper is organized as follows. We first present the problem statement in section 2. The implementation of AHP, TOPSIS and the utility function are given in section 3. The details of the case study for the implementation of the proposed model is presented in section 4. Finally, concluding remarks are given in section 5 to summarize the contribution of the paper.

\section{Problem Statement}

Let $n$ be the number of facilities which are supposed to be connected and $x_{i}$ with $i=1, \cdots n$ be a binary variable which is one when a facility is chosen and zero, otherwise. Let $a_{k i}$ be a binary parameter which is one when a connection between facility $k$ and $i$ is possible and zero, otherwise. Therefore, a classical set covering is formulated as follows,

$\min \quad z=\sum_{i=1}^{n} x_{i}$

subject to

$\sum_{i=1}^{n} a_{k i} x_{k i} \geq 1, \quad k=1, \cdots n$

$x_{i}=0,1 . \quad i=1, \cdots, n$

Problem (1) is a zero-one programming and the optimal solution determines the minimum number of facilities which are supposed to be connected. As we discussed earlier, we may not often choose a facility solely based on the minimum number of connections and there may be other criteria to be considered. Let $c_{i}$ be the qualitative desirability associated with location $i$. Therefore, we may wish to maximize this objective function along with the first one as follows,

$$
\begin{aligned}
& \min z_{1}=\sum_{i=1}^{n} x_{i} \\
& \max \quad z_{2}=\sum_{i=1}^{n} c_{i} x_{i}
\end{aligned}
$$

subject to

$\sum_{i=1}^{n} a_{k i} x_{k i} \geq 1, \quad k=1, \cdots n$

$x_{i}=0,1 . \quad i=1, \cdots, n$ 
Problem (2) is a multi objective decision making (MODM) problem where there are two objectives to be optimized. In order to determine a suitable value for $c_{i}$ we may need to consider various factors such as whether condition, available infrastructures, political issues, etc. Zanjirani Farahani and Asgari, (2007) suggested four important issues as important factors affecting set covering decision making to select a location: 1 . Whether conditions which includes temperature, humidity, numbers of sunny and rainy days. 2. National defense which includes internal and external threats, etc. 3. Economic issues which include the availability of human resources, financial institutions, etc. 4. Infrastructures which include the availability of roads, airports, railroad, etc. Among these factors, one may choose the best ones based on the expert's opinions and a Delphi procedure (Hwang \& Yoon, 1981). The next step for quantifying the experts' decitions is to find the relative importance of the qualitative features. This could be done using analytical hierarchy procedure and finally a methodology based on TOPSIS is used to find the overall ranking for different alternatives (Hwang \& Yoon, 1981). The details of the implementation of TOPSIS are discussed in the next section.

As we have explained, the proposed model of this paper is formulated as multi-objective zero-one programming and we need a utility function to handle the objectives into a single objective function so that the resulted model could be directly solved using a direct implementation of mixed integer programming. Suppose we solve problem (2) two different times by considering only one of the objective functions $z_{1}$ and $z_{2}$, each time. Let $z_{1}^{*}$ and $z_{2}^{*}$ be the optimal objective functions of the resulted solutions, respectively. In order to build a utility function we use two weights of $w_{1}$ and $w_{2}$ with $w_{1}+w_{2}=1$. Therefore, the utility function used in this paper is as follows,

$$
u=w_{1}\left(\frac{\sum_{i=1}^{n} x_{i}-z_{1}^{*}}{z_{1}^{*}}\right)+w_{2}\left(\frac{z_{2}^{*}-\sum_{i=1}^{n} x_{i}}{z_{2}^{*}}\right) .
$$

Problem (1) can be solved by using (3) as the objective function. Note that the norm used to build the objective function does not change the nature of the classical set covering, i.e. the problem remains linear in terms of variables. Next section, we explain the implementation of the resulted problem formulation for a case study of truck industry.

The optimal solution of model (3) determines the suitable alternatives selected as DCs and the other alternatives are selected as retailers. However, the proposed model does not specify the relationship between the retailers and DCs. Therefore, we use the method proposed by Zanjirani Farahani and Asgari (2007) to handle this problem. They introduce a new form of binary variable called $y_{k l}$ which gets a value one in case retailer $k$ is assigned to distribution center $l$ and it gets zero, otherwise. Let $p$ be the optimal number of DCs and $B_{m \times p}=\left[b_{i k}\right]$ be the new form of $A_{m \times n}=\left[a_{i j}\right]$ where all columns associated with $x_{j}=0$ are eliminated. Therefore we have,

$$
\min \sum_{i=1}^{n} w_{k} b_{k l} y_{k l}
$$

subject to

$$
\begin{aligned}
& \sum_{l=1}^{q} b_{k l} y_{k l}=1, \quad k=1, \cdots n \\
& y_{k l}=0,1 . \quad k=1, \cdots, n, \quad l=1, \cdots, q
\end{aligned}
$$

The optimal solution of model (4) determines the relationship between retailers and DCs. 


\section{The case study}

In this section, we present the details of the case study used to validate the proposed model of this paper. One of the most important problems in supply chain management is to locate suitable distributer centers (DC) to minimize the costs of transportation among various cities in Iran where the case was studied. The truck company studied in this paper attempts to locate some cities as DC and the remaining cities as retailers. The company was estabilished in 2009 and the primary objective of this company is to act as a truck part supplier. In order to find suitable criteria as qualitative attributes, we performed a brain storming discussion among experts. In our survey, we have selected five attributes of cost, accessibility, weather growth potential and economic advantages as the most important attributes. We have also compared them based on AHP procedure and the summary of all pairwise comparisons are summarized in Table 1.

\section{Table 1}

Qualitative criteria chosen with AHP ranking numbers

\begin{tabular}{llllll}
\hline Criteria & Cost & Accessibility & Weather & $\begin{array}{l}\text { Growth } \\
\text { Potential }\end{array}$ & $\begin{array}{l}\text { Economic } \\
\text { Advantages }\end{array}$ \\
\hline Cost & 1 & $1 / 3$ & 5 & 7 & 5 \\
Accessibility & 3 & 1 & 5 & 9 & 9 \\
Weather & $1 / 5$ & $1 / 5$ & 1 & 5 & 3 \\
Growth Potential & $1 / 7$ & $1 / 9$ & $1 / 5$ & 1 & 3 \\
Economic Advantages & $1 / 5$ & $1 / 9$ & $1 / 3$ & $1 / 3$ & 1 \\
\hline
\end{tabular}

As we can observe from Table 1, we have used Likert (Likert, 1932) measure from 1 to 9 to show the relative importance of different attributes in pair wise comparisons. For instance, accessibility is much more important than growth potential when we compare these two attributes. Applying the AHP procedure yields the following ranking for all five attributes.

Table 2

The relative importance of five different attributes

\begin{tabular}{lccccc}
\hline Item & Cost & Accessibility & Weather & Growth Potential & Economic advantages \\
\hline rank & 0.234375 & 0.25 & 0.109375 & 0.1875 & 0.1185 \\
\hline
\end{tabular}

As we can see from Table 2, the second item, Accessibility, is the most important issue on choosing DCs. The cost of building DC comes the second most important item and growth potential, economic advantages and weather condition come after. The next step is to assess the relative importance of these five items for different alternative cities. Again, we have used a Likert scale (Likert, 1932) from 1 to 9 representing from the least to the most importance measures. Table 3 summarizes the details of the ranking for all candidate cities.

The next step is to find the relative importance of all these 30 cities. Note that we desire to have the maximum values for all five attributes used in this research. Therefore, the implementation of TOPSIS could help us find measurement with the minimum norm value among all these five attributes. The last column of Table 3 summarizes the relative importance of all 30 cities based on the implementation of TOPSIS method. The ranking numbers are used for $c_{i}$ when model (2) is solved using the second objective function to find $z_{2}^{*}$. Once we gathered all the necessary information used to solve model (2) and (3), we may solve the resulted model using a simple mixed integer software package. We have solved the resulted model using LINGO software. Our implementation solves model (1) in two phases. In the first phase, model (1) is solved with two objective functions $z_{1}$ and $z_{2}$ , two different times, sepesatly and then we build the utility function (3) using the optimal values of $z_{1}$ and $z_{2}$. In the second phase we find the final efficient solution using different values of $w_{1}$ and $w_{2}$. Table 4 summarizes the results of our implementation for the case study of this paper. 
Table 3

The details of the ranking for various cities

\begin{tabular}{|c|c|c|c|c|c|c|}
\hline City & Cost & Accessibility & Weather & Growth Potentials & Economic Advantages & TOPSIS \\
\hline Kerman & 5 & 3 & 9 & 5 & 3 & 0.4756 \\
\hline Oroumieh & 7 & 7 & 5 & 7 & 7 & 0.5238 \\
\hline Esfehan & 9 & 9 & 9 & 9 & 9 & 0.4860 \\
\hline Yazd & 7 & 7 & 9 & 9 & 5 & 0.5238 \\
\hline Tabriz & 9 & 7 & 5 & 9 & 7 & 0.9525 \\
\hline Mashhad & 9 & 5 & 9 & 7 & 7 & 0.4682 \\
\hline Shiraz & 7 & 7 & 9 & 9 & 7 & 0.5242 \\
\hline Zahedan & 5 & 5 & 9 & 7 & 3 & 0.4835 \\
\hline Ardebil & 5 & 7 & 5 & 9 & 5 & 0.9631 \\
\hline ShahreKord & 5 & 5 & 9 & 7 & 3 & 0.4836 \\
\hline Tehran & 9 & 9 & 9 & 9 & 9 & 0.4860 \\
\hline Hamedan & 7 & 9 & 9 & 7 & 7 & 0.0760 \\
\hline Sanandaj & 5 & 5 & 9 & 5 & 7 & 0.4841 \\
\hline Bandarabbas & 7 & 7 & 5 & 7 & 7 & 0.5238 \\
\hline Sari & 7 & 5 & 5 & 5 & 5 & 0.0273 \\
\hline Rasht & 7 & 5 & 5 & 5 & 5 & 0.0273 \\
\hline Gorgan & 7 & 5 & 5 & 5 & 5 & 0.0273 \\
\hline Ahvaz & 7 & 5 & 5 & 7 & 7 & 0.0420 \\
\hline Kermanshah & 7 & 5 & 9 & 7 & 7 & 0.0458 \\
\hline Arak & 7 & 9 & 9 & 7 & 9 & 0.0834 \\
\hline Ilaam & 5 & 3 & 9 & 7 & 7 & 0.4767 \\
\hline Bojnord & 5 & 5 & 9 & 9 & 5 & 0.4842 \\
\hline Boshehr & 7 & 5 & 5 & 7 & 5 & 0.0317 \\
\hline Birjan & 5 & 5 & 9 & 5 & 5 & 0.4836 \\
\hline KhoramAbad & 5 & 5 & 9 & 7 & 7 & 0.4843 \\
\hline Zanjan & 7 & 9 & 9 & 9 & 7 & 0.0805 \\
\hline Semnan & 7 & 9 & 9 & 9 & 7 & 0.0805 \\
\hline Ghazvin & 7 & 9 & 9 & 9 & 7 & 0.0805 \\
\hline Ghom & 7 & 9 & 9 & 9 & 5 & 0.0760 \\
\hline Yassoj & 5 & 7 & 9 & 5 & 3 & 0.9437 \\
\hline
\end{tabular}




\section{Table 4}

The details of the DC allocation for different values of $w_{1}$ and $w_{2}$

\begin{tabular}{|c|c|c|c|c|}
\hline City & $w_{1}=.5, w_{2}=.5$ & $w_{1}=.7, w_{2}=.3$ & $w_{1}=.3, w_{2}=.7$ & $w_{1}=.4, w_{2}=.6$ \\
\hline Kerman & $\mathrm{DC}$ & Retailer & DC & DC \\
\hline Oroumieh & $\mathrm{DC}$ & Retailer & $\mathrm{DC}$ & DC \\
\hline Esfehan & DC & Retailer & DC & DC \\
\hline Yazd & $\mathrm{DC}$ & Retailer & DC & DC \\
\hline Tabriz & $\mathrm{DC}$ & DC & DC & DC \\
\hline Mashhad & $\mathrm{DC}$ & Retailer & DC & DC \\
\hline Shiraz & DC & Retailer & DC & DC \\
\hline Zahedan & $\mathrm{DC}$ & Retailer & DC & DC \\
\hline Ardebil & $\mathrm{DC}$ & $\mathrm{DC}$ & DC & DC \\
\hline ShahreKord & $\mathrm{DC}$ & Retailer & DC & DC \\
\hline Tehran & $\mathrm{DC}$ & Retailer & DC & DC \\
\hline Hamedan & Retailer & Retailer & Retailer & Retailer \\
\hline Sanandaj & $\mathrm{DC}$ & Retailer & DC & DC \\
\hline Bandarabbas & $\mathrm{DC}$ & $\mathrm{DC}$ & DC & DC \\
\hline Sari & Retailer & Retailer & Retailer & Retailer \\
\hline Rasht & Retailer & Retailer & Retailer & Retailer \\
\hline Gorgan & Retailer & Retailer & Retailer & Retailer \\
\hline Ahvaz & Retailer & Retailer & Retailer & Retailer \\
\hline Kermanshah & Retailer & Retailer & Retailer & Retailer \\
\hline Arak & Retailer & Retailer & Retailer & Retailer \\
\hline Ilaam & $\mathrm{DC}$ & Retailer & DC & DC \\
\hline Bojnord & $\mathrm{DC}$ & DC & DC & DC \\
\hline Boshehr & Retailer & Retailer & Retailer & Retailer \\
\hline Birjan & $\mathrm{DC}$ & Retailer & DC & DC \\
\hline KhoramAbad & $\mathrm{DC}$ & Retailer & $\mathrm{DC}$ & DC \\
\hline Zanjan & Retailer & Retailer & Retailer & Retailer \\
\hline Semnan & Retailer & Retailer & Retailer & Retailer \\
\hline Ghazvin & Retailer & Retailer & Retailer & Retailer \\
\hline Ghom & Retailer & Retailer & Retailer & Retailer \\
\hline Yassoj & $\mathrm{DC}$ & $\mathrm{DC}$ & DC & DC \\
\hline
\end{tabular}


As we can observe from Table 4, once we assign more values to the second item, we see different patterns for DC allocation which means the qualitative criteria play important role on the set covering decision making problem. Fig. 1 shows the implementation of model (4) for our case study.

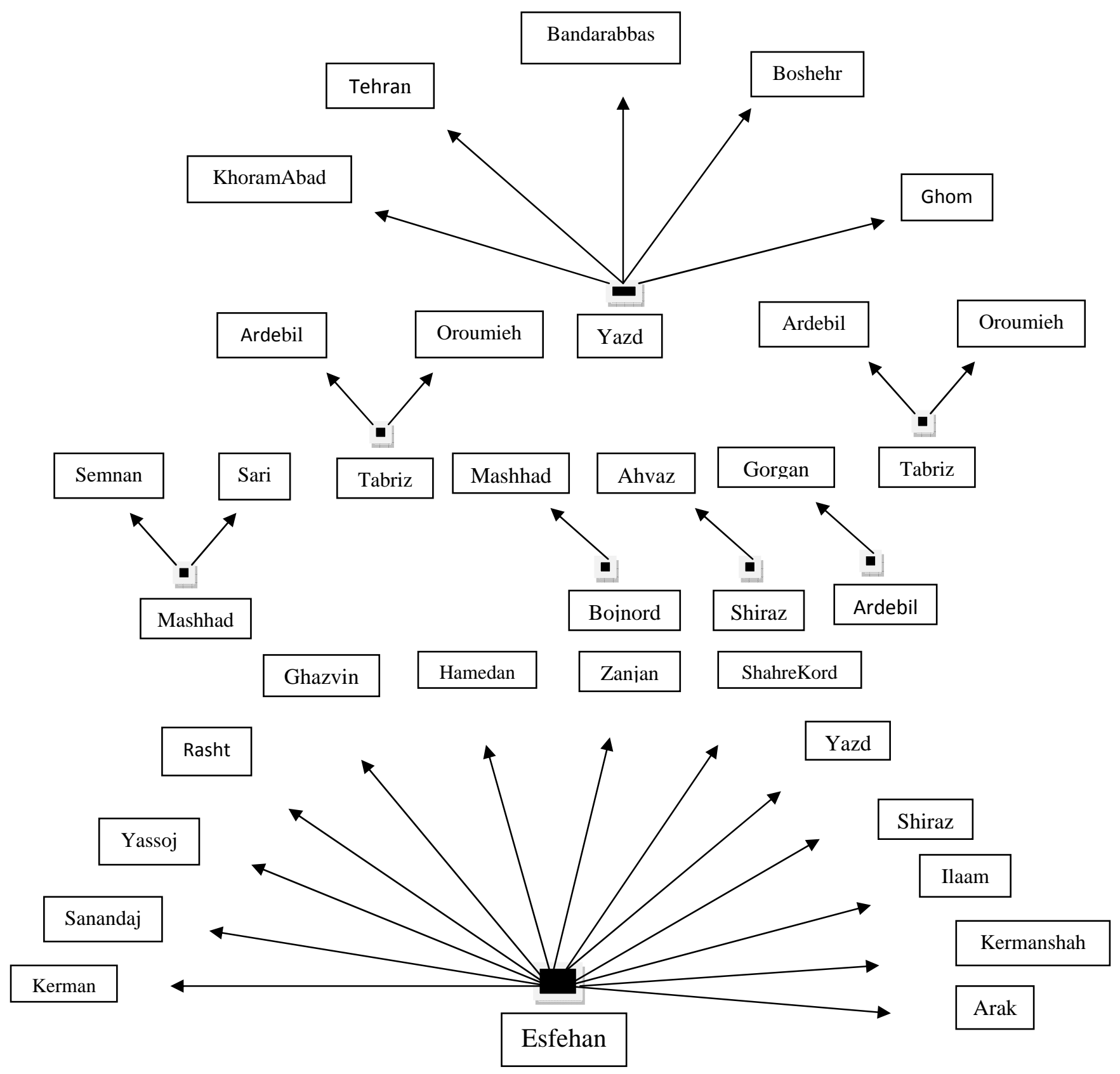

Fig. 1. The relationship among destributtion centers and retailers $\left(w_{1}=.5, w_{2}=.5\right)$

\section{Conclusions}

In this paper, we have presented a new multi-objective set covering problem with two types of quantitative and qualitative objective functions. The qualitative objective was quantified using AHP and TOPSIS and they were combined in a unique objective fucntion using a simple 1-norm with two different weights. The proposed model has been implemented to a real-world application of truck industry and the results are analyzed by studying various scenarios. The preliminary results indicate that the new method could provide efficient solutions when qualitative factors play an important role on our decision. As a future research, we could consider uncertainty with the distances between the cities. Such a problem can be formulated in the context of robust optimization. Presently, there is no 
relationship among distribution centers in the proposed modeling formulation but it is possible to have such a situation for real-world problems. There are also other cases where we already have some active DCs and the problem is to add additional DCs. In this case we face with two scenarios as to whether we keep the old ones as active DC or cancel parts of the old ones and consider the new alternatives.

\section{Acknowledgment}

The authors gratefully thanks the anonymous referees for their remarks that improved the quality of this paper.

\section{References}

Aickelin, U., (2003). An indirect genetic algorithm for set covering problem. Journal of the Operations Research Society, 53(10), 1118-1126.

Araz, C., Selim, H., \& Ozkarahan, I. (2005). A Fuzzy multi-objective Covering-based Vehicle Location model for emergency services. Computers \& Operation Research.

Berman, O., Krass, D. \& Prezner, Z. (2003), The gradual Covering decay Location Problem on a network. European Journal of Operational Research, 151, 474-480.

Boffey, B., \& Narula, S. C., (1997). Multiobjective covering and routing problems. In: Karwan, M.H., Spronk, J., Wallenius, J. (Eds.), Essays in Decision Making: A Volume in Honour of Stanley Zionts. Springer, Berlin

Chiang, C. I., Hwang, M. H., Liu, \& Y. H. (2005). An Alternative Formulation for Certain Fuzzy SetCovering Problems, Mathematical and Computer Modeling, 42, 363-365.

Church, R., \& ReVelle, C. (1974). The maximal covering location problem. Papers of the Regional Science Association, 32, 101-118.

Francis, R.L., McGinnis, L.F., \& White, J.A.(1992). Facility Layout and Location: An Analytical Approach, $2^{\text {nd }}$ ed. Prentice-Hall, Englewood Cliffs, NJ.

Hale, T. S. \& Moberg, C. R. (2003). Location Science Research: A Review, Annals of Operations Research, 123, 21-35.

Hwang, C. L., \& Yoon, K., (1981). Multiple Attribute Decision Making. Springer, New York.

Klose A., \& Drexl, A. (2005). Facility location models for distribution system design, European Journal of Operational Research, 162, 4-29.

Korsvik, J. E., Fagerholt, K., \& Laporte, G., (2011). A large neighbourhood search heuristic for ship routing and scheduling with split loads. Computers \& Operations Research, 38(2), 474-483.

Likert, R. (1932). A Technique for the Measurement of Attitudes. Archives of Psychology, 140, 1-55.

Vasko , F. L., \& Wilson, G. R. (1984), Using A facility location algorithm to solve large set covering problems, Operations Research Letters.

Nozick, L. K. \& Mark A. (2001), Turnquist, Inventory, transportation, service quality and the location of distribution centers, European Journal of Operational Research, 129, 362-371.

Schilling, D., Jayaraman, V., \& Barkhi, R., (1993). A review of covering problems in facility location. Location Science 1, 25-55.

Solar, M., Parada, V. \& Urrutia, R. (2002), A Parallel genetic Algorithm to solve the set-Covering Problem, Computers \& Operation Research, 29, 1221-1235.

Zanjirani Farahani, R. \& Asgari, N. (2007), Combination of MCDM and covering techniques in a hierarchical model for facility location: A case study, European Journal of Operational Research 176, 1839-1858

Zyl, J. V., \& Cloete, I.,(2006). Specialization models for a general fuzzy set covering framework. Fuzzy Sets and Systems, 157(21), 2787-2808. 